\title{
SEXIST EXPRESSIONS IN NYAKYUSA
}

\author{
Musa Saimon \\ College of Business Education, Dodoma, Tanzania \\ bromusa40@gmail.com
}

Manuscript received 21 March 2020

Manuscript accepted 6 June 2020

*Corresponding author

https://doi.org/10.33736/ils.2150.2020

\begin{abstract}
The way people use language determines and (or) reflects their experience in their social context; the use of everyday language becomes a lens through which people behave and see their world and at other time it is the social practices that influence certain choices of language used by community members. For that reason, research on how languages affect women's image in different speech communities is highly needed for the sake of saving women's face. This brought to the attention the concept of language and gender in applied linguistics whose focus is on how language use and labelling is associated with gender differences. And those language forms that show gender bias are known as sexist expressions. Drawing on this particular scenario, the present study explores sexist expressions in Nyakyusa language using data collected from four Nyakyusa speaking people as key informants through mobile phone interviews. Data were analysed thematically in which I generated themes from coded and categorised data. Findings show that Nyakyusa exhibits elements of sexism through five forms of sexist expressions, namely, referential gender, social gender, lexical gender, proverbs and idioms and agreements. The researcher calls for creation of awareness among Nyakyusa speech communities for reformation of sexist expressions
\end{abstract}

Keywords: Nyakyusa language; Nyakyusa speaking Community; Sexist expressions; Forms of sexist Expressions

\section{Introduction}

The way people use language reflects their socialization (experience) within a certain (Eckert \& Mcconnell-Ginnet, 2003; Gee \& Handford, 2013; Lakoff, 1975). The perception of a certain speech community towards a certain entity determines the proper way of expressing such entity or event. For example, in a community where it is perceived that talking back to elderly person is immoral, such acts may be described as resistance while on the other hand for those who perceive it as moral behaviour, it can be regarded as argumentation.

Research shows that different speech communities demonstrate their negative perceptions towards women through their speeches which are termed as 
sexist expressions (Litosseliti \& Sunderland, 2002; Throsby \& Alexander, 2008). However, the rise of feminism (women's movement for women's right in the society) has put human languages under scrutiny for its contribution towards women's discrimination in their communities, which resulted into restructuring sexist expressions (Mills, 2008; Weatherall, 2002). English language is among the languages whose patterns were modified to redress the image of women. Some of the sexist expressions which were modified include replacing the word "chairperson" for "chairman" and use of generic pronouns for men only and "she" for "women", only to mention a few.

Despite the fact that there are general language patterns through which sexism can be expressed in human language, research shows that certain language patterns can be present in language A while absent in language B (Hellinger \& Bussmann, 2001; Hellinger \& Bußmann, 2003; Meyerhoff \& Holmes, 2003). For instance, English pronouns are gender based in the sense that "he" is used for men while "she" is used for women. Meanwhile in Swahili there is no such difference in personal pronouns. As such, the researcher's motivation in exploring the sexist expressions in Nyakyusa language is to address the question of gender discrimination in Nyakyusa speaking community.

\section{Nyakyusa Language}

Nyakyusa is among Bantu languages spoken in Mbeya (Kyela and Tukuyu) and some parts of Malawi. Like any other languages, Nyakyusa has a number of varieties/dialetcs. Maho (2009, cited in Persohn, 2017) provides three major dialects, namely, nyakyusa of lake-shore plains which sometimes is referred as Ikyangonde, Central Nyakyusa which is spoken around Masoko and Nyakyusa of Mountains which covers large part of tukuyu district. Among these dialects, central nyakyusa is regarded to be the most prestigious one (Persohn, 2017), and it is the one the present study is based on.

\section{Forms/Patterns of Sexism in Human Language}

Different languages exhibit sexism through different patterns or forms as presented in (Mills, 2008; Hellinger \& Bubman, 2001; Litosseliti \& Sunderland, 2002; Weatherall, 2002). However, this study adopts classifications of such patterns/forms from (Hellinger \& Bußmann, 2001, 2003) which are:
a) Grammatical gender
b) Lexical gender
c) Referential gender
d) False generic (generic masculine)
e) Social gender
f) Gender related to structure
g) Agreement
h) Pronominalization
i) Coordination of conjoined nouns
j) Proverbs and idioms 
Grammatical gender involves the language having differentiation between men and women in its grammar specifically on personal pronouns such as "he" and "she" in English language (Hellinger \& Bußmann, 2001, 2003; Mills, 2008). In addition, lexical gender is all about the language having different lexical terms such as adjectives for men and women. For example, in Swahili "dada" (sister) is special for women while "kaka" (brother) is for men (Hellinger \& Bußmann, 2003; Litosseliti \& Sunderland, 2002; Mills, 2008).

On top of that, referential gender means when certain references in the language are made to a single gender (women). For example, in Swahili "mwanamwari" denotatively means a person who is hidden inside as he nears his/her marriage; nevertheless, connotatively it is referenced only to women (Hellinger \& Bubman, 2003). Besides that, false generic (generic masculine \& male generic) is concerned with the state whereby male pronoun/noun is used for all human beings (Hellinger \& Bußmann, 2001, 2003; Mills, 2008). For example, in Swahili the word "binadam" has its roots in "bin adam" which means the son of Adam, however, it is used as the general reference for all human being (Hellinger \& Bußmann, 2003)

Apart from that, social gender is based on how certain statuses are perceived to belong to men only or women while it is not an inherent character of such status (Hellinger \& Bußmann, 2001, 2003). Moreover, gender related structure involves word formation process whereby women related words, are embedded with diminutive elements (Hellinger \& Bußmann, 2001, 2003). Furthermore, agreement gender is concerned with how certain character or behaviour is assumed to fit only men or women despite being inherently a possibility of both genders (Hellinger \& Bußmann, 2001, 2003; Mills, 2008). For example, in English language the word "strong" agrees with men, not women as if women cannot be strong. Thereafter, pronominalisation involves how the very same name when used for men and women undergo some changes to fit each gender (Hellinger \& Bußmann, 2001, 2003). For example, in English, the word "actor" is used for men while women are referred to as "actresses".

Above all, proverbs and idiomatic expression as language patterns for sexism involves how some proverbs or idioms glorify men while undermining women (Hellinger \& Bußmann, 2001, 2003). Therefore, in the present study, the classifications by Hellinger and Bußmann $(2001,2003)$ will serve as a benchmark for exploring sexist expressions in Nyakyusa language.

\section{Related Studies}

The claim that all languages are sexist seems to be less debatable (Lei, 2006; PrewittFreilino, Caswell, \& Laakso 2012). This is due to the fact that many language communities are built on a patriarchal system which seems to be the root of sexism in language. However, the fact that different languages have different forms of expressing sexism makes the research on forms or parameters of sexism in languages becoming of great interest among scholars. Lei (2006) and Demberg (2014) observed that sexism in English language is overtly shown through naming, generic pronouns, gender referential, social gender, proverbs and idioms. While Lei 
(2006) provides an instance of sexism in English through professional names where the word doctor seems to be appropriate only for men, Demberg (2014) reports that in British newspapers, women are referred by surnames of their husbands, which makes women lose their personal identity.

On the other hand, the report of UMWA (2016) showed English sexist expressions in the media in Uganda. According to UMWA (2016) the language used in media is embedded with sexism through referential gender, social gender, names and address terms. For instance, it is reported that in one story narrated in the media, men were referred to as bosses while women were regarded as servants and sometimes women are labeled in relation to their private parts like "thigh vendors" (UMWA, 2016). Furthermore, Mmadike (2014) revealed that sexism in Igbo language of Nigeria is overtly exhibited through proverbs. He provides one proverb that is translated in English as "If a woman claims equality with a man, let her urinate upward", which is said to any woman who tries to force her to achieve something. The use of such proverb, which implies men's supremacy over women being rooted in their biological differences, lowers women's image in the society, thus making them feel incapable. In contrast, Ifechelobi and Ifechelobi (2017) observed the way in which Igbo language fits into the group of sexist languages through referential gendering and social gender giving an example of the word "agbala" as used in the novel "Things Fall Apart". They argue that the word "agbala" means "an old woman", however, when it is used to refer to men, implies a man without any title, thus having negative connotation.

Moreover, Alhassan (2012) conducted a study on sexism in Dabanli, the language spoken in Ghana. He found that proverbs, naming, social gender and gender referential are common forms through which sexism is expressed in Dabanli. He reports that in Dabanli unmarried and divorced women are called "buzawara" which has negative connotation while there is no negative label for unmarried men. This implies that marriage is compulsory for women as it makes them earn social prestige. Alhassan (2012) went further by showing an example of sexist proverbs in Dabanli such as "woman does not cut the head of the snake" whose interpretation is that women cannot make hard decisions. The use of such proverbs raises inferiority among women in making decisions and leaves men with a monopoly of power in decision-making (Alhassan, 2012). In connection to that, referential gender in Dabanli is exhibited through dishwashing activities whereby men who get involved in such activities are given names with negative connotation such as " $a$ do loo". This implies that dishwashing activity is for people with low social status especially women.

IsiZulu, Kinyarwanda and Setswana of South Africa, Rwanda and Botswana respectively are among sexist Bantu languages. Atanga, Ellece, Litosseliti, and Sunderland (2012) observed that the naming system in isizulu is based on gender bias since men and women of the same statuses are named with words whose connotations do not have similar implications. For instance, the name given for men who have an affair with many girls is "amasoka" (men highly favored by girls) while the name for women with many sexual partners is "isifebe" (loose woman) or "isichebeleshe" (useless woman). In contrast, Kinyarwanda and Setswana demonstrate sexism through agreement whereby the verb marry takes the 
masculine subject only, meaning that only men are active participants in marital union.

Ndimande-Hlongwa and Rushubirwa (2014), when comparing Isizulu and Swahili conclude that both languages show sexism through gender referential. They reported that in Isizulu there are names for women who exceeded the social expected age for marriage and those who have lost their virginity, which implies that marriage is only prestigious for women and that only women are limited to practise sexual intercourse until marriage. For instance, a woman who has exceeded the expected time for marriage is known as "Umjendevu". It is also reported that men and women with many sexual partners are labelled differently whereas men's labels have positive connotations while women's labels have negative connotations. For example, "isoka" (a man with many lovers) is used for men while "isifibhe" (the woman with many lovers) is used for women. Ndimande-Hlongwa and Rushubirwa (2014) posit that the name "isifebhe" has its origin in a large hole used to entrap large games. Thus, this implies that women are holes and men are games, and "isifebhe" underrates women. While women are discouraged from sexual activity before marriage in isizulu speech community, men are encouraged to engage in sexual activity before marriage. For instance, Ndimande-Hlongwa and Rushubirwa (2014) report that men who do not have sexual partners are called "isishimane" (the man who is not popular with women), which implies that having lovers for men is creating prestigious social identity.

In contrast to IsiZulu, Swahili language shows sexism through agreement, social gender and idioms and referential gender (Ndimande-Hlongwa \& Rushubirwa, 2014). In their study Ndimande-Hlongwa and Rushubirwa (2014) report that the Swahili verb "Oa" (marry) agrees only with masculine subjects which implies that only men are the active participants in the event, thus monopolosing power. They went on to reveal that although "bwana/bibi" (Mr/Mrs) are used for men and women respectively for showing respect, when "bibi" is used on its own does not reserve the same respect it has when used together with "bwana". This shows the extent to which references for women are only connoting respect when accompanied with references for men. "Amepata jiko" (He has a stove/kitchen) is Swahili idiom which is used to refer to a man who has got married. The comparison of a woman with a kitchen demonstrates the extent to which women are associated with domestic activities such as cooking (Ndimande-Hlongwa \& Rushubirwa, 2014).

Likewise, Viergutz (1994, as cited in Hellinger \& and Bußmann, 2003) reveals how social gender, generic nouns and referential gender are dominant forms of sexism in Swahili language. It is reported that the word "vijana", though primarily is the plural of "kijana" (young man), is normally used as reference for both girls and boys. In addition to that, the word "rafiki" and "shoga" connote friendship. Nevertheless, the word "shoga" when used to men carries a negative connotation (homosexual) while the word "rafiki" is used for both sexes (Hellinger \& Bußmann, 2003). Such instances imply the extent to which women are less respected in Swahili speaking community.

Therefore, it is clear that different languages show different forms of sexism through different forms of expressions in such a way that, one language cannot be 
enough to give a base for generalisation, thus a need to explore sexist expression in Nyakyusa language.

\section{Methodology}

The present study is qualitative in nature. Qualitative research involves human behaviour in their natural settings (Hennink et al., 2011).

The data were collected from four native speakers of Nyakyusa through mobile phone interviews who were selected through purposive sampling. Purposive sampling involves setting of specific criteria for sampling (Hennink, Hutter, \& Bailey 2011). In the present research, only Nyakyusa native speakers were selected. I chose to interview female and male native speakers whose age is above 40 for getting data from people whose native language competence is not affected by other languages, while the choice for two females and males was aimed at balancing the gender.

In the current study, only four participants were involved: there were two females and two males. The choice for using only four participants was determined by the point of data saturation. Data saturation point is when there is no new data emerging from participants.

Data were analysed thematically. Thematic analysis involves coding and categorising data to generate themes (Hennink et al., 2011; Lodico, Spaulding, \& Voegtle, 2006). Having collected data, the researcher grouped them based on their connotation in relation to male and female identity in the Nyakyusa speaking community to develop themes. The researcher employed member checking strategy to ensure correctness of the analysis. Member checking is the strategy of validating themes from the data collected by involving participants to justify themes (Creswell \& Miller, 2000).

\section{Findings}

In this study, I explored forms of sexist expressions in Nyakyusa language. This section presents the findings of the present study as shown in the Table 1.

Table 1

Forms of sexist expressions in Nyakyusa

\begin{tabular}{ll}
\hline $\begin{array}{l}\text { Sexist forms } \\
\text { explored }\end{array}$ & Examples \\
\hline Referential gender & $\begin{array}{l}\text { Mwalangani (not calm or settled mindedly) } \\
\text { Ngang'ara (a very old person, especially a woman) } \\
\text { Malafyale (an address for a man whose connotation is } \\
\text { chief/king) }\end{array}$ \\
\hline Social gender & $\begin{array}{l}\text { Bhusungu (having qualities of a white race normally used to } \\
\text { refer to part of bride price (cows) which is special for a virgin } \\
\text { girl) } \\
\text { Bhugumba (infertility, normally used as reference for a } \\
\text { woman) }\end{array}$ \\
\hline
\end{tabular}




\begin{tabular}{|c|c|}
\hline Lexical gender & $\begin{array}{l}\text { Ndindwana (girl) } \\
\text { Ndumyana (boy) } \\
\text { Mwa+clan name (for a boy child) for instance Mwa+kajila } \\
\text { Kana+clan name (for a girl child) for instance Kana+kajila } \\
\text { Guso (informal address for father) } \\
\text { Nyoko (informal address for mother) }\end{array}$ \\
\hline $\begin{array}{l}\text { Proverbs } \\
\text { idioms }\end{array}$ & $\begin{array}{l}\text { Abhakikulu kyala gwabho afwile (women's God had died) } \\
\text { Ubhukenja mbhungo (bachelorhood is a disease) }\end{array}$ \\
\hline Address & $\begin{array}{l}\text { Nka+husband name (prefix of ownership used for reference of } \\
\text { someone's wife) } \\
\text { Gwakilingo (an expected heir, normally used as a reference } \\
\text { for a boy child) } \\
\text { Gwang'ombe (an expected source of cows, normally referred } \\
\text { to girl child) }\end{array}$ \\
\hline Agreement & Ega (To marry) \\
\hline
\end{tabular}

\section{Discussion}

As shown in Table 1, there are six forms of sexist expressions in Nyakyusa, namely, referential gender, social gender, lexical gender proverbs and idioms, addresses and agreement. The finding that shows sexist expressions in Nyakyusa language through referential gender is similar to that of UMWA (2016) in English language, Ifechelobi and Ifechelebi (2017) in Igbo language, Alhassan (2012) in Dabanli, and Hellinger and Bußmann (2003) in Swahili language, in which there a number of words with negative connotations are referred to women only. in Nyakyusa the words like such "mwalangani" and "ngang'ara" which literally mean a person who is unsettled mindedly and an old person respectively, are mostly connoted as "prostitute" and "worthless person" respectively, when referred to women. In contrast, the word "malafyale" which means chief or king is only used as reference to men to show respect. This implies that in the Nyakyusa speaking community, women are perceived to be of less respect compared to that given to men.

Social gender is among forms of sexist expressions observed in Nyakyusa. This finding is similar to what UMWA (2016), Atanga et al. (2012), and NdimandeHlongwa and Rushubirwa (2014) observed in English, Isizulu and Isizulu and Kiswahili respectively in there is asymmetry association of certain social status between men and women. In Nyakyusa language, there are words that refer to women who are found to be a virgin during marriage time and for women who do not bear children. For instance, when the girl is found to be virgin during marriage time, the man has to pay part of the bride price known as "ing'ombe ja bhusungu" (cow for virginity), which implies that virginity is among the aspects of women's value in Nyakyusa speaking community. Besides that, the word "ngumba" (incapable to bear children) is only used for women as if there are no men who are impotent. As a result, in many Nyakyusa speaking communities, women are victims of the problem related to child bearing.

It was also found that lexical gender in Nyakyusa as a form of sexist expression has shown both symmetrical and asymmetrical relationships between 
men and women since there are expressions that show no difference between men and women as well as those which are gender biased. This finding is similar to that of Ndimande-Hlongwa and Rushubirwa (2014) on Swahili language. Words such as "ndindwana" (girl) and "ndumyana" (boy), "nkikulu" (woman) and "nnyambala" (man) are some of expression under lexical gender with symmetrical relationship between men and women, thus being similar to "kijana" (boy) and "binti" (girl) in Swahili as reported in Ndimande-Hlongwa and Rushubirwa (2014).

In contrast, words like "guso" (an informal reference for father), "nyoko" (an informal reference for mother) and clan names for women and men represent expressions with gender biased implications. Although "guso" and "nyoko" have similar denotative meaning, the word "nyoko" sometimes is used as an insult, which makes such reference being perceived less respectful compared to reference for male parents. This is similar to what Hellinger and Bußmann (2003) report that, in Swahili women's private parts are used as offensive language because women are perceived to be uncontrollable sexually.

The question with clan names in Nyakyusa originates from the nature of prefixes used for each gender. The prefix "kana" (small child) which is used for women implies diminutive qualities while the prefix " $m w a$ " (one who belongs or is associated with) which is used for men connotes association or belongingness only. This argument might sound strange among some nyakyusa speaking people and thus I am obliged to give some comparative examples to clarify my point as indicated in the following:

1. Kana ka kajila (Kanakajila)

The mall female child of kajila

2. Kana ka ngo'mbe (kanang'ombe) (calf)

Small child of a cow

3. Mwana gwa kajila (mwakajila)

The male child of kajila

4. Mwana gwa kulya (mwakulya)

A man of eating/ a man who is associated with eating/ a man who like eating

Based on (1), (2), and (4), one may find that the way prefixes "kana" and " $m w a$ " are used in context of making reference to clan names and other names shows how "kana" is associated with the size of the referent while " $m w a$ " is associated with the bond of the referent. Therefore, such bias is likely to motivate nyakyusa-speaking communities to perceive women as less important as they are associated with diminutive features.

Furthermore, Nyakyusa idioms and proverbs were found to be sexist since their connotations have negative implications to women. This finding is similar to that of Mmadike (2014), Alhassan (2012) and Ndimande-Hlongwa and Rushubirwa (2014) on Igbo, Dabanli and Swahili language respectively. The idiom "abhakikulu kyala gwabho afwile" (god of women had died) is used when a woman is at fault implying that women do not have senses, but when a man commits mistakes, there is no idiom for ridiculing him. There is another saying "nyakyusa-ubhukenja 
mbhungo" (bachelorhood is a disease) which is gender-biased. This saying is used in a context where a man faces some difficulties in accomplishing some of his plans especially those related to domestic activities implying that, if a wife was there, she could have done such activities for a man. As a result, in marriage of nyakyusaspeaking communities, women are perceived to be men's servants. However, the belief is religiously affiliated as in the bible it is written that God made Eve to help Adam (Genesis 2:18 New International Version).

On the other hand, it was found that other sexist expressions in Nyakyusa are in the form of address terms. This is similar to the findings related to English and Swahili language as revealed by Demberg (2014) and Ndimande-Hlongwa and Rushubirwa (2014) respectively whereby addresses for men imply more respect than address terms for women. In Nyakyusa there is an address for a married woman, which shows is a wife of somebody but there is no address for a man to show that he is a husband of somebody. This implies that in Nyakyusa speaking community only women are regarded to be owned by men rather than men being owned by women. For instance, a woman who is married to Musa is addressed as "nkamusa" which originates from the "nkasi gwa musa" (the wife of Musa) but the man whose wife is Neema, there is no way can be addressed as "nduneema" which originates from "ndume gwa Musa" (the husband of Neema). Consequently, in Nyakyusa speaking communities men are allowed to have more than one wife but not a woman having more than one husband.

Additionally, a girl child in Nyakyusa is addressed as "gwang'ombe" (a source of cows) implying that after marriage the family will get cows (pride price) while a boy child is addressed as "gwakilingo" (an expected heir) implying that after the death of the father he will control the family. This is similar to the UMWA'a (2016) report that men are reffered as "bosses" while women are reffered as "thigh vendors". Such differences in address terms demonstrates a very huge gender bias since girl children are underrated by being associated with properties that a family can earn through her marriage while a boy child is associated with personal capacity of controlling a family. This can act as one of the motivating factors behind women's lack of involvement in decision making in Nyakyusa speaking communities.

Overall, it was found that sexism in Nyakyusa is expressed through agreement whereby the verb "ega" (to marry) agrees with masculine subject only. This finding is similar to what Atanga et al. (2012) observed in Kinyarwanda and Setswana and what Ndimande-Hlongwa and Rushubirwa (2014) observed in Swahili. The fact that the verb to marry agrees only with masculine subject implies that marriage relationship in Nyakyusa is perceived to be one sided as men are regarded to be more active than women to make the union, thus women losing their power.

\section{Conclusion}

This study aimed to explore sexist expressions in Nyakyusa. Findings show that referential gender, social gender, lexical gender, proverbs and idioms, address terms and agreement are common forms of sexist expressions in Nyakyusa. Following the strong relationship existing between language and social practices, the researcher calls for projects that create awareness among Nyakyusa-speaking communities for 
reforming sexist expressions. The findings of the present study demonstrate the extent to which Nyakyusa is a sexist language in a similar way as other languages such as English, Igbo, Dabanli, Isizulu, Kinyarwanda, Setswana and Swahili. Arguably, there is a strong association between Nyakyusa language structures with Nyakyusa social structures.

\section{References}

Alhassan, S. (2012). Language and gender. The construction and reproduction of gender in Dagbanli. (Unpublished PhD Thesis). University of Ghana.

Atanga, L., Ellece, S., Litosseliti, L., \& Sunderland, J. (2012). Gender and language in Sub-Saharan African contexts: Issues and challenges. Gender and Language 6(1), 1-20.

Creswell, W., \& Miller, W. (2000). Determining validity in qualitative inquiry. Theory into Practice, 39(3), 124-130.

Demberg, R. (2014). Linguistic sexism: A study of sexist language in a British online newspaper. (Unpublished PhD Thesis). Linnaeus University.

Eckert, P., \& Mcconnell-Ginnet, S. (2003). Language and gender. New York: Cambridge Press.

Gee, P., \& Handford, M. (2013). The Routledge handbook of discourse analysis. New York, NY: Routledge.

Hellinger, M., \& Bußmann, H. (2001). Gender across languages: The linguistic representation of women and men. Amsterdam, Netherlands: J. Benjamins.

Hellinger, M, \& Bußmann, H. (2003). The linguistic representation of women and men. Gender across languages, 2, 1-26.

Hennink, M., Hutter, I., \& Bailey, A. (2011). Qualitative research methods. Thousand Oaks, CA: SAGE.

Ifechelobi, C., \& Ifechelobi, N. (2017). Gender discrimination: An analysis of the Language of Derogation'. IOSR Journal of Humanities and Social Science, 22(12), 23-27.

Lakoff, R. (1975). Language and woman's place. New York, NY: Harper \& Row.

Lei, X. (2006). Sexism in Language. Journal of Language and Linguistics, 5(1), 87-94.

Litosseliti, L., \& Sunderland, J. (2002). From representation towards discursive practices: Gender in the foreign language. Amsterdam, Netherlands: John Benjamins Publishing Company.

Lodico, G., Spaulding, T., \& Voegtle, K. (2006). Methods in educational research : From Theory to Practice. San Franscisco: Jossey-Bass.

Meyerhoff, M., \& Holmes, M. (2003). The handbook of language and gender. Berlin: Blackwell Publishing Ltd.

Mills, S. (2008). Language and sexism. Cambridge: Cambridge University Press.

Mmadike, I. (2014). The Igbo perception of womanhood: Evidence from sexist proverbs. Research in Humanities and Social Sciences, 4(18), 98-104.

Ndimande-Hlongwa, N., \& Rushubirwa, L. (2014). Gender inequality and language reflections in African indigenous languages: Comparative cases from Isizulu and Kiswahil. Alternation, 390-410. 
Persohn, B. (2017). The verb in nyakyusa: A focus on tense, aspect, and modality. Berlin, Germany: Language Science Press.

Prewitt-Freilino, L., Caswell, T., \& Laakso, K. (2012). The gendering of language: A comparison of gender equality in countries with gendered, natural gender, and genderless languages. Sex Roles, 66(3-4), 268-281.

Throsby, K., \& Alexander, F. (2008). Gender and interpersonal violence: Language, action and representation. New York: Springer.

UMWA. (2016). Media and elections in Uganda: A gender analysis of print media Coverage of the 2016 General Elections. Uganda Media Women's association (UMWa)

Weatherall, A. (2002). Gender, language and discourse. New York: Routledge 